

\author{
INTERNATIONAL JOURNAL OF \\ HERITAGE, ART AND MULTIMEDIA \\ (IJHAM) \\ wWw.ijham.com
}

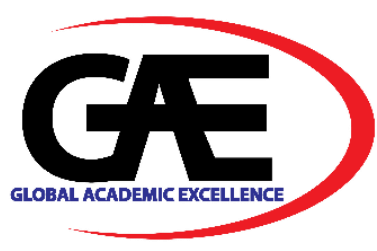

\title{
'THE INVIABLE AND VIABLE UNIQUE CHARACTER OF SILVERPOINT DRAWING FROM THE PAST TO CURRENT PRACTICE'
}

\author{
Ernesto Carlos Pujazon Patron ${ }^{1 *}$, Jose Domingo Elias ${ }^{2}$, Fuad Arif ${ }^{1}$, Mumtaz Mokhtar $^{1}$ \\ 1 University Technology MARA, Malaysia \\ Email: hsecpp@gmail.com* \\ 2 Potificia Universidad Catolica del Peru, Peru. \\ Corresponding Author
}

\section{Article Info:}

Article history:

Received date:01.12.2021

Revised date: 12.12 .2021

Accepted date: 24.12 .2021

Published date: 31.12 .2021

To cite this document:

Patron, E. C. P., Elias, J. D., Arif, F., \& Mokhtar, M. (2021). 'The Inviable and Viable Unique Character of Silverpoint Drawing From The Past To Current Practice'. International Journal of Heritage, Art and Multimedia, 4 (15), 100-118.

DOI: $10.35631 /$ IJHAM.415009.

This work is licensed under CC BY 4.0

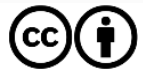

\begin{abstract}
:
The use of Metalpoints such as silver, bronze (Brass), copper, gold or lead are of the most gentle and delicate techniques applied by the Renaissance masters in Europe predating the introduction of graphite. There is a wealth of detailed information available online. Metalpoint was a popular drawing and writing technique from the 14th to the early 16th century. This technique involves dragging a metal-stylus across a substrate coated with a somewhat abrasive emulsion leaving small particles of metal dust over the surface to create a mark. These metal-rods oxidate over a different period of time which is altered by the environmental circumstances, changing the drawing appearance. Similar to a pencil rendering, the silver line oxidises and becomes black. Although it is difficult to utilise metalpoint to produce a specific tiny mark, it is a desired tool for a highly talented draughtsman. This paper discusses the practical approach to substrate preparation; the hatching and cross-hatching technique employed by the masters and contemporary artists in addition to the provocative drawing and sensual rendering impact of the finished drawing.
\end{abstract}

Keywords:

Silver Point, Metal Point(s), Drawing, Drawing Technique, Metal-Stylus

\section{Introduction}

Long before the invention of the graphite lead tool, the metal-rod stylus was the method used for conveying any fine drawing over a prepared surface. This was a practice commonly performed prior to and during the Renaissance period by most of the distinguished artists of the time such Jan Van Eyck, a painter from Bruges who was one of the early innovators of Copyright $\odot$ GLOBAL ACADEMIC EXCELLENCE (M) SDN BHD - All rights reserved 
Volume 4 Issue 15 (December 2021) PP. 100-118

DOI 10.35631/IJHAM.415009

what became known as the Early Dutch painting representing the Northern Renaissance; Leonardo da Vinci, an Italian polymath of the high Renaissance who was an active painter, engineer, theorist, sculpture and architect; Albrecht Dürer, German painter, print-maker and theorist and Raphael Sanzio da Urbino, an Italian painter and an architect of the High Renaissance among other significant artists of the time. Metal-rods, such as silver, copper, bronze, gold or lead can be used on a variety of supports such as paper, parchment and panelwood; however, these surfaces must need to be prepared with special emulsion for the metalrod to leave a mark. Naturally, the colour of the substrate is off-white but it also can be tinted in light shades of red, pink, brown or light blues, as some Renaissance drawing has shown. Once the substrate is coated and the abrasiveness of the surface increased, the stylus rubs off and the substrate has sufficient 'teeth' to retain these tiny particles of metal dust. Each metalrod has its unique softness and oxidation period with the exception of gold, which does not vary over time (Drawing Academy, 2013). Since the Renaissance, there has been some revival in using metal-rod techniques as a medium of expression; Pablo Picasso, Joseph Stella, Susan Schwalb, Carol Prussa, Jasper Johns in the $20^{\text {th }}$ century are positive examples. Contemporary artists have also expanded their choice of supports-substrate, often working with tinted grounds that alter the effect of the metal point employed, for example fiberglass with fiber-optic cable on black gesso, which aims to intensify the final drawing outlook. Using a silver point like any other metal points produces a delicate shimmer and fine line that is improved when the metal begins to tarnish. Indeed, one of Leonardo's early drawings executed as a student in the late 1470s in Florence, is one of the most admired drawings in the history of art and is considered one of the highest points of the medium. It is drawn with a silver stylus on a specially coated paper (Cumming 2015), it shows an excellent and meticulously skilled drawing of a soldier in a helmet, (Figure 1, beneath). This sketch-drawing or study provides an unforgettable demonstration of the subtlety and precision offered by the silver point indicating his ability as draughtsman, placing each arrow-straight hatching line with such accuracy that from a few inches away the parallel lines creates and impression of soft flesh. The delicate modelling of the face forms a prominent contrast to the calligraphy handling of the warrior's armour and the crunchy contour of the profile, strengthened as the artist reinforced the silver point line by tracing over it a few times. Silver point was a method of practice that all apprentices were expected to do, thus gaining control and discipline of line and shading before moving on to other types of tasks. This method of drawing never left the Italian workshop to enter the artists' private lives as it did in northern Europe. Flemish artists drew their wives and siblings, their children and pets (Cumming, 2015). Hilton Brown, an American Post-war and Contemporary painter, explained in the book "Looking a Painting" that metalpoint drawing, "is an exacting technique requiring commutate control of both mind and hand' (Antoine, 2007, p. 3). 


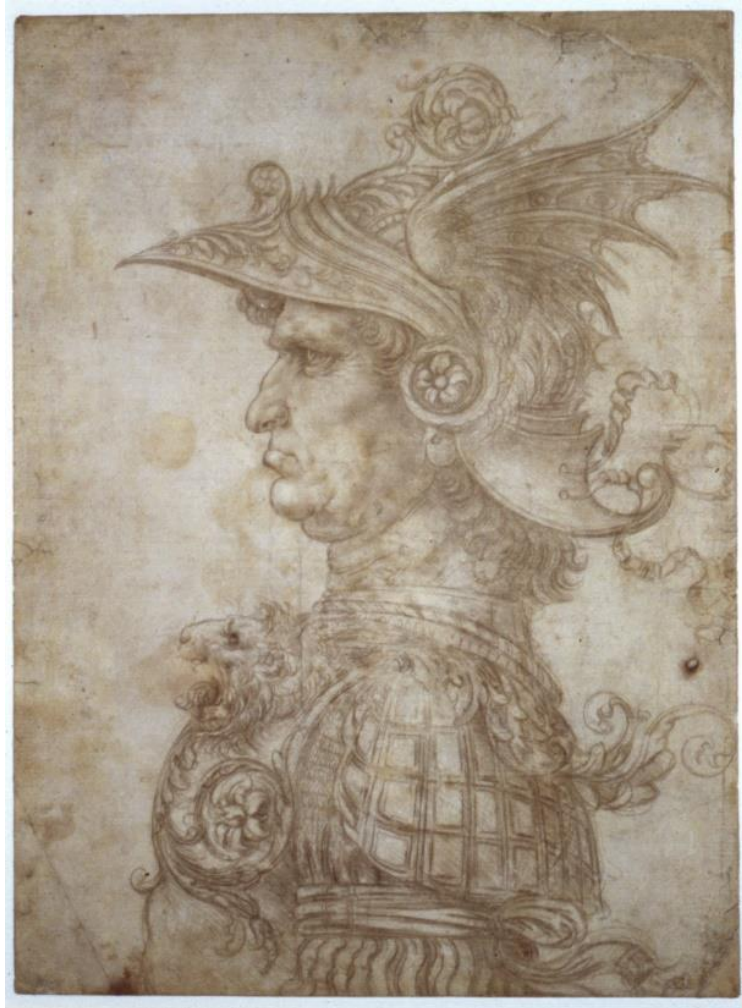

Figure 1: Leonardo Da Vinci (1452-1519). "Bust of a Warrior in a Winged Helmet". (c, 1475-1480). Silverpoint on paper. $28.7 \mathrm{~cm} \times 21.1 \mathrm{~cm}$. (Photograph: @ Trustees of the British Museum)

There are three important themes that this paper would like to address: (1) A practical approach to the preparation of various surfaces such as watercolour paper, cardboard, cartridge paper, wood, as well as textured and nontextured substrate; each type of surface brings advantages and disadvantages over the development of new drawing methods; (2) changes in the use of these hatching and crossed hatching techniques to which drawing were put as a result of these needs, from the objective development of composition and from the preliminary sketch idea to the completed formulated design, introducing three artist examples such as Leonardo, Jan Van Eyck, and Durer; and (3) the exciting and provoking effect on their artistic practices has brought about and their pictorial preoccupations of the idea development. Ames-Lewis refers to them as "sculptural drawings" (Wohl, 1984, 336); which can be seen in the artwork produced by Carol Prusa and Susan Schwalb. What matters in these studies is not whether a drawing was made by Leonardo, Van Eyck, Durer or any of their contemporary artists such as Prusa or Schwalb, but rather how it was created and what creative challenges the draftsman attempted to solve. During the $15^{\text {th }}$ century, realistic rendering of the naked figure of a human body in a three-dimension space was a means of exploring new challenges. Early Renaissance drawings were significant but not so much as expressions of unique creative personalities or as expressions of individual artistic personalities than as records of the development in naturalistic rendering. The key enquiry about the drawing was not who made it, but what difficulties it addressed and how the artist dealt with them. In the pursuit of addressing these issues, it is better to establish the meaning of the term, "drawing" in the context of fine arts. Harold Speed (1972) in the book, 'The practice and science of drawing' 1972, states: By drawing is here meant the expression of 'form' upon a plane surface' (31). Giorgio Vasari (1511-1574) judges 


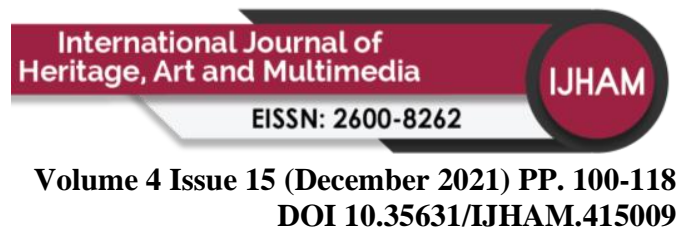

drawing as a means of expression and details study to be superior to finished works, due the fact that this creative process happens in the artist's mind before it is settled down and recorded on a surface (Wohl 1984, 336). In the, 'Lives of the most excellent Painters, Sculptors and architects' (Le Vite 1550), Giorgio Vasari distinguishes between studied drawing which he calls 'disegni' (design) which reproduces the idea in the mind of the artist, like for example, 'nature' if that idea is clear, and 'schizzi' (sketch) which is executed in the breath of inspiration or in the heat of the moment 'furor' (excitement). The creative process is something that the artist must take well into consideration to study. It could be in a manner of objective (logical) or in the manner of expression (emotional). This notion can be documented by drawing or a theoretical discussion, advancing our understanding of the creative process from the viewpoint of the artist's mind. The history of art probably owes more to 'form' for its range of expressions rather than to colour. It is interesting to notice how some of the greatest artists are very restricted with the use of colours and prefer to depend on the 'form' for their chief appeal. Every student of art should pursue a well-trained eye with all the might of which he/she is capable. It is not enough to reproduce the form of an object with artistic accuracy. It demands that things-objects to be observed by a sentient individual, recording these feelings produced in them by the singularities of life (Speed 1972, p. 36). There are no absolute standards of artistic accuracy which an artist may follow or a work of art may be judged, and such standards vary from the artist's artistic intention. Another important point to bring into discussion is how the eye fails to pay attention to the richness which an artist presents before us. The psychology of the vision tells us that seeing must be selective from the start and that is the way the eye responds to this selection which is physiological and psychological (Gombrich, 1979, p. 94).

\section{Discussion And Results}

Prior to the Middle Ages and Renaissance times, scribes were trained to use metal rods for drawing. Besides, text designs and illustrations, chalks and inks were also employed. Be that as it may, metalpoint was superior in some very specific ways; it was fine enough to capture exquisite details and would not smudge (unlike chalks or charcoals). This medium was also completely permanent, inert to fade-proof, marks were indelible, erasure was impossible except with careful scrapping or sanding the ground. It made an excellent method for underdrawings, remained as it would not stain, so egg gum base tempera painters could continue with the colour application. Two important characteristics of Silverpoint technique are: 1) subtlety of tone in the lighter end of the tonal grey scale; 2) single hatching or cross-hatching strokes are the result of an extremely uniform sensuous surface. Old masters and contemporary artists, who are most successful at silverpoint drawing are those with deep concern for the aesthetic pleasure and the beauty of the surface. By the end of the $16^{\text {th }}$ century, drawings made of graphite lead stick, were wrapped in a string of sheepskin for stability. It became popular when a massive deposit of graphite was discovered in Borrowdale valley, a civil parish in the English Lake District of Allerdale in Cumbria. Plumbago, a Latin name, also known as black lead, became a commodity of extremely high quality (Krug 2007, p. 42). This pure form of graphite was known as 'wad' used in 'lead pencils.' This discovery surprised the locals because they didn't know what this material was. It looked like coal, but it did not burn and they noticed that it could produce the darkest marks better than the lead used for marking sheep. It was not until the $18^{\text {th }}$ century that a Swedish chemist, Carl Wilhelm Scheele (1742-1786) discovered that the substance was crystalized carbon and named it 'graphite', from the Greek word for writing, 'Graphein.' (Krug 2007, p. 42). Metal-stylus as a writing instrument was known to the Romans and was first used in Western art around 1100 AD. It was a thin metal stick, made from lead strips to scratch on papyrus sheets or wax tables. The word, "pencil" is derived from the Latin for "pencillus" or 


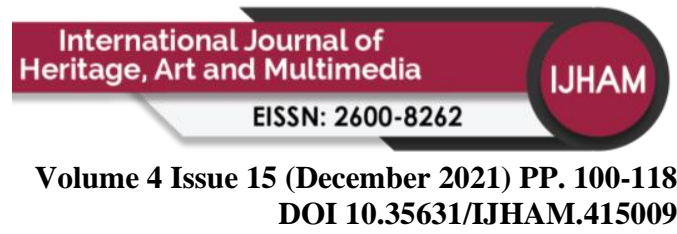

'little tail'. The "pencil' as we know it today was invented by Nicolas-Jacques Conté (17551805) of France in 1795 (Britannica, T. Editors of Encyclopaedia (2003, March 11), pencil drawing summary). Although this technique has passed into disuse, metal-stylus has been used since antiquity. In Western-Europe, the pinnacle of the hey-days can be situated in the $15^{\text {th }}-16^{\text {th }}$ century. Cennino d'Andrea Cennini (1360-1427), in a well-known book, 'Il Libro dell'Arte', $(c, 1400)$ - (The Craftsman's Handbook), indicates that metalpoint drawing should be used for under-drawing in painting (Dik, 2008, p. 382). Metalpoint is a descendant from the metal-stylus of classical times and an ancestor to the modern pencil as it is known today (Britannica, T. Editors of Encyclopaedia (2016, October 18). metal point). Master artists used it for a precise sketch of the human figure and compositional drawing on a specially coated surface. This technique is most suitable for being precise and firm. At the time of the $15^{\text {th }}$ and $16^{\text {th }}$ century, metalpoint drawings were carefully preserved in a workshop portfolio and it served as a reference for future compositional designs, providing a stock of figures and examples of foreign animals and plants (Dahn, 2004, p. 80).

Metals such as gold, copper, bronze or lead (plumb) are used (Figure 2: a, b, and c below). However, silver is the common choice and it is most suitable for permanent drawings that produces an extremely delicate pale grey line which is perfect or ideal for pictures or portraits, textiles (drapery), fruits and plants (Botanical Illustrations), and it strokes adhering inerasably (Krug 2007, p. 48). Silver leaves a faint grey line that will turn warmer as it tarnishes over time to mellow browns and no other medium can surpass this method (Speed, 1972, p. 275). It also produces a great spotless clean and clear line which is required, for instance by miniaturist and calligraphy design in original manuscripts (Anderson et al., p. 2019).

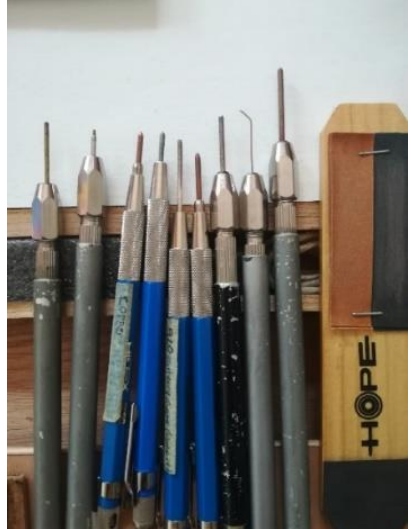

a)

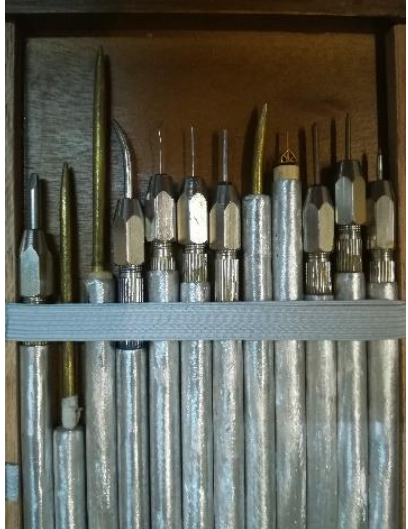

b)



c)

Figure 2: Metal-rods (a, b, c): Silver, Gold, Copper, Bronze-Brass, Lead. (Author Drawing Tools)

This technique is used for underdrawings in panel paintings as well as for delicate detail drawing known as 'fine art drawing'. By the seventeenth century, this style decreased perhaps due the introduction of the mass production of the pencil lead graphite, which was much easier to erase or remove. Silverpoint drawing has a light airy quality and the marks produced have a narrow value range somewhat like those produced by a hard lead such a 'HB' pencil. It is an advantage to use it for underdrawings on wooden panels for tempera and water-colour paintings because it shows through far less than charcoal or any other drawing materials (Krug, 2007, p. 48). In the $15^{\text {th }}$ century, this method of drawing achieved a great deal of popularity by the Flemish, German, and Italian artists (Figure 3 below). 
Volume 4 Issue 15 (December 2021) PP. 100-118

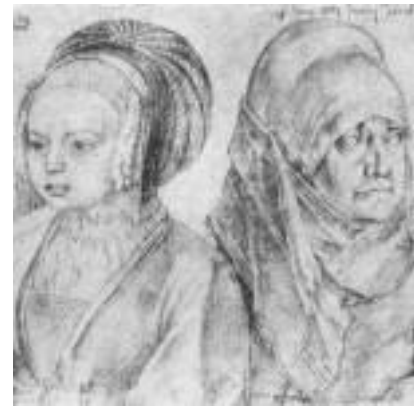

a)

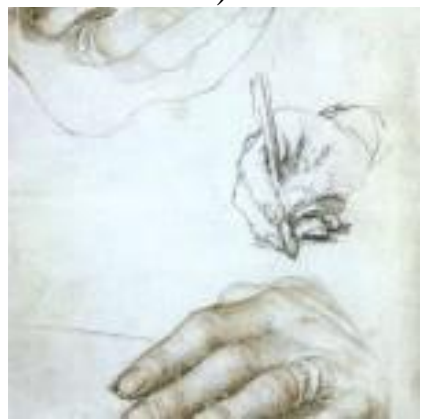

d)



b)

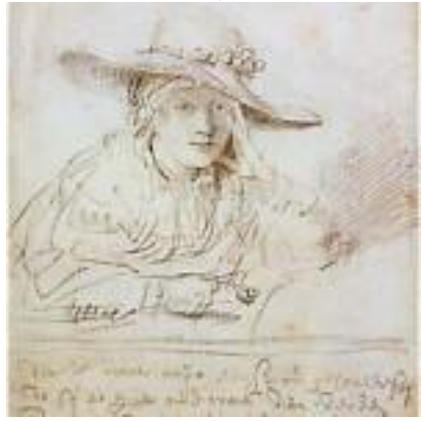

e)

DOI 10.35631/IJHAM.415009



c)

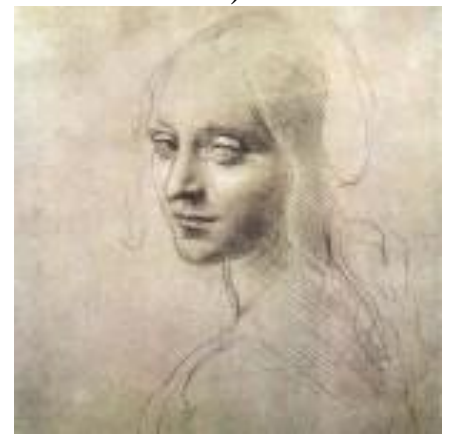

f)

Figure 3: Silverpoint on paper, from left to right. (a) Albercht Durer. A Young Girl in Cologne Dress - Portrait of Agnes Durer (Wife) 1521. (b) Albercht Durer. Two Seated Lions, 1521. (c) Rogier van der Weyden. St. Mary Magdalene, 1450 (d) Hans Holbein

the Younger. 'Hand Study of Erasmus of Rotterdam' (c, 1523). (e) Rembrandt Harmenszoon van Rijn. 'Saskia van Uylenburgh' (c, 1633). (f) Leonardo Da Vinci. 'Study for Head of Angel in Madonna of the Rocks' (c, 1483-85)

Art is not a sustitute for nature but an expression of feelings produced in the conciousness of the artist and is intimately associated with the materials through which it is expressed in the work (Speed, 1972, p. 272). This technique is one in which especially silver or other hard metals are used instead of graphite to create a drawing. During the period of the $15^{\text {th }}-16^{\text {th }}$ century, drawings using metalpoints were normally not signed and most of the works were executed at the workshop either by the masters or by the apprentices by following the masters' instructions. Cennino Cennini, describes this method as a necessary skill for any apprentices 'to approach the glory of the profession'. Silver point leaves a tiny amount of silver dust on the surface of the paper once it is coated, so a drawing can be re-drawn many times without any significant attrition of silver dust. In general, drawings are not mass produced and only are done by a well-trained hand after the master of the workshop has approved him or her (Alfeld et al., 2009). Highlights usually done with other mediums are common practices, usually using white lead paint in the form of water colour or if the drawing is a base for an oil painting. There is a significant number of drawings showing this combination of metal-rod, ink, and white paint.

This paper presents a discussion as an attempt at describing the metalpoint drawing produced by the old masters and the observations on how the contemporary methods of using the metalpoint technique are used on different types of surfaces nowadays. Even though silverpoint does not produce any darkest range of marks in the black and white scale value of greys, this method can effectively be used for scientific illustrations, particularly if it is used in conjunction with other mediums such as carbon dust-charcoals, chalks, graphite pencils or Copyright $\odot$ GLOBAL ACADEMIC EXCELLENCE (M) SDN BHD - All rights reserved 
Volume 4 Issue 15 (December 2021) PP. 100-118

DOI 10.35631/IJHAM.415009

water colours. These other mediums enhance the illustration outcome. Botanical illustration or naturalist drawings began to appear at around the end of the $14^{\text {th }}$ century in the work of some artists (Morley, 1979, p. 554) who were eager to record the nature in all its forms. This method relies on the usage of colours along with the use of metalpoint, producing a fine grey and futile line. In this medium of expression, the artist not only captures the essence of the object but also documents the object structure, and captures the exterior texture of the physical form and shape in exquisite accurate detail. Besides, colours may be translated by the degree of shades the artist is able to re-create and re-produce.

\section{1) Practical Approach: The Preparation of Substrate and Metal-Rods Description.}

A wide variety of art materials, books, and recipes can be found on the internet. Each recommends different manners in preparing the surface for a drawing. It all depends on the final outcome an artist may want to achieve; for metalpoint drawings, the common support for this method requires a semi-rigid surface such as paper, parchment, cardboard or wooden panel. These surfaces are coated with an emulsion of commercial white acrylic paint currently available in the market. Cennino Cennini's treatise, "Il Libro dell'Arte", (c, 1400), is considered by conservators and historians as the most reliable source for the historical reconstruction of artist working methods in Florentine workshops of the late trecento and the Quattrocento (Burns, 2011, p. 1). It describes practices and provides recipes and instructions for metalpoint drawing and support preparation that continue to be used into the $16^{\text {th }}$ century (Dahn, 2004, p. 79). Besides, it also recommends bone ash tapped with saliva on a small board, or added on animal rabbit-glue and alum for elasticity, combined with colour pigment and lithopone (a mixture of barium sulphate and zinc sulphide) which help darken the silver rod (Krug, 2007, p. 101). Currently, artists depend on the ready-made products such as the whitetitanium acrylic mixed with zinc oxide powder, added to some clean or distillate water. The ideal recipe may vary from artist to artist, and mostly the proportion is based on the artist's own experience. It is recommended that the surface be primed 3 to 4 times, and it depends on the thickness of the paper, cardboard or wooden panel, with vertical and horizontal strokes covering the entire surface. The thickness of the primed surface is important because it may allow the artist to remove any line which was made by mistake, by using sand paper or by scratching the surface. The addition of some other colour pigment to this mixture creates coloured surfaces for further drawing studies, and this was actually a normal way used by old masters. Every single metal rod has a unique property of undergoing different reactions and oxidations to environmental humidity.

a) Silver, 999 is the purest and is also the finest and softest rod, while the 835 is the hardest rod, and both are commonly used by artists and old masters to produce a permanent finest and untainted line, which will be tarnished over time to warm brown or light black oxidation;

b) Gold, is the most noble and precious of all metals that produces a warm grey mark, and it is also permanent and does not tarnish over time. Both silver and gold rods are pleasant to work with;

c) Copper, as a reddish-orange colour is often used as an alloy ingredient that produces a grey mark that tarnishes to a greenish-yellow shade;

d) Bronze (Brass), is another alloy used with copper and zinc, and it tarnishes to a light black oxidation shade; 
Volume 4 Issue 15 (December 2021) PP. 100-118 DOI 10.35631/IJHAM.415009

e) Nickel silver, is a combination of copper, zinc and nickel, and it shows a white silvering appearance. It is also known as German silver, and it tarnishes too to a greenish or bluish shade;

f) Lead or plumbum from the Latin, is a soft and malleable metal, it does not need a coated surface, and it can be erased by a blunt tool. It is toxic and it tarnishes too to a dull grey shade when it is exposed to air and moisture; and,

g) Pewter, is a good alternative to lead, made of tin and copper and it is non-toxic and soft. It can be used in most coated surfaces becoming blunt quicker than other metal-rods. In drawing the condition of metal-rod abrasion may be perceived from the ground changing colour. Oxidation varies by length of time and place. In general, copper usually starts to oxidate in one or two months, and silver takes from four up to six months at slow rates. The life of the metal-rod depends on the usage, which normally lasts almost a lifetime. Within the same drawing, areas of dense strokes may appear brownish and lighter areas may appear golden (Dahn, 2004, p. 75).

2) Changes: The Use of Techniques Such as Hatching and Cross-Hatching.

The pursuit of a sensuous beautiful surface is one of the aims of meticulous drawing. For the past 500 years artists in each period have maintained fine shading, attention to texture and surface appearance as a priority for fine rendering. Many talented painters lack the light touch and sensitivity to produce a sensuous texture on paper. Silverpoint perhaps is the ultimate medium for artists to achieve it. (Figure 4: (a) \& (b) beneath)



a)

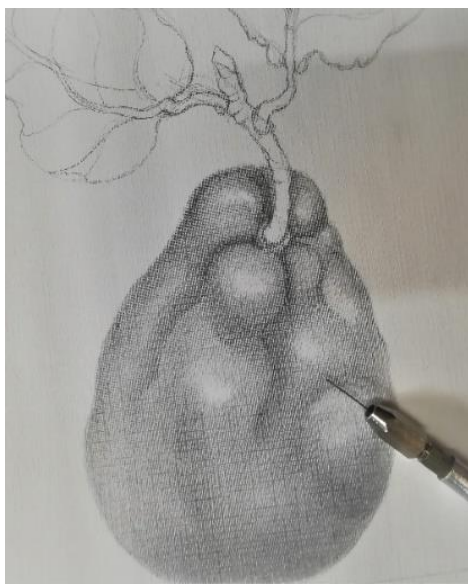

b)

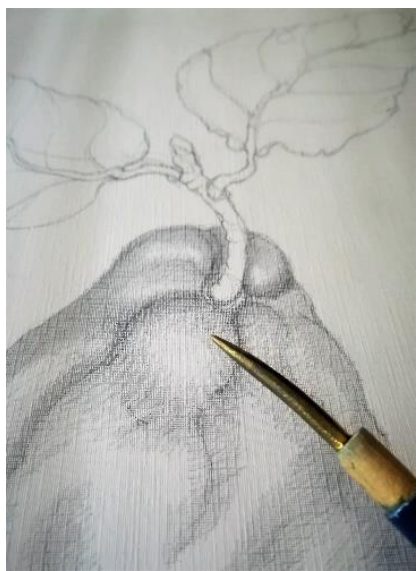

c)

Figure 4: (a, b) Pear I, 2021. Silverpoint on water-colour paper. $21 \mathrm{~cm}$ x $29.5 \mathrm{~cm}$. c) Brass/bronze-point on cartridge paper. $21 \mathrm{~cm} \times 29.5 \mathrm{~cm}$. (Author drawings)

Hatching is the repetition of parallel lines to create broad areas of tone that conveys volume and depth, as well as the representation of the object shadows. Cross-hatching, involves parallel lines which are crossed by other sets of parallel lines creating a dense grid-like pattern. (Figure 5 , beneath), in the context of fine art drawings, the rule of thumbs is: 'the stronger the pressure on the stylus-pencil is, the darker the line may appear'. 


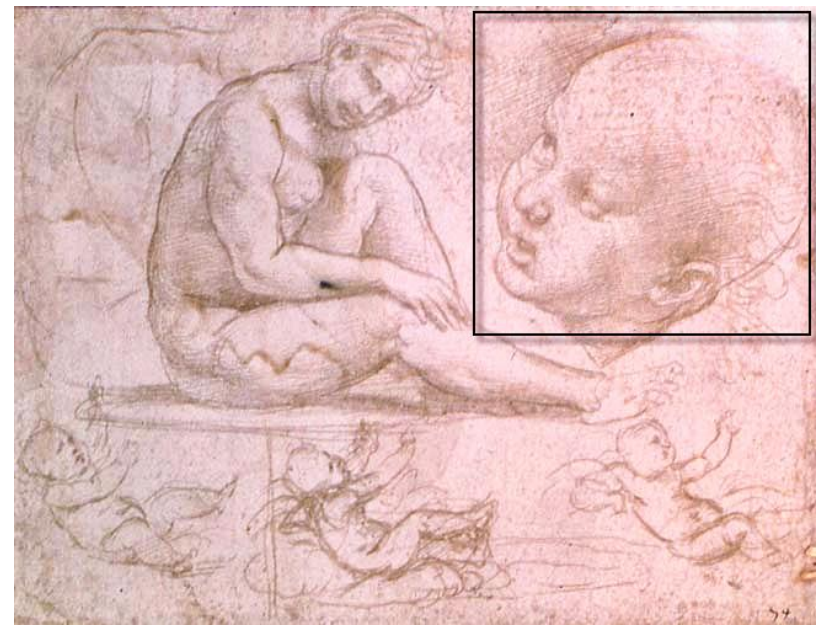

Figure 5: Raffaello Sanzio da Urbino, best known by 'Raphael' (Italian, 1483-1520) Detail from Studies of a Seated Female, Child's Head, and Three Studies of a Baby. (c, 1507-08). Silverpoint on cream laid paper prepared with a pink ground, $12 \mathrm{~cm} \times 15.3$ cm.

Artists can also employ contour lines to create the object's shape and volume, which are most commonly utilised on rounded surfaces like cylinders, spheres or in the studies of the human form shown below. (Figure 6, beneath). The human form is one of the most enduring themes in the history of the visual arts, indeed it is the basis for the portrait, painting sculpture, medical illustration and other fields of social science and technology.

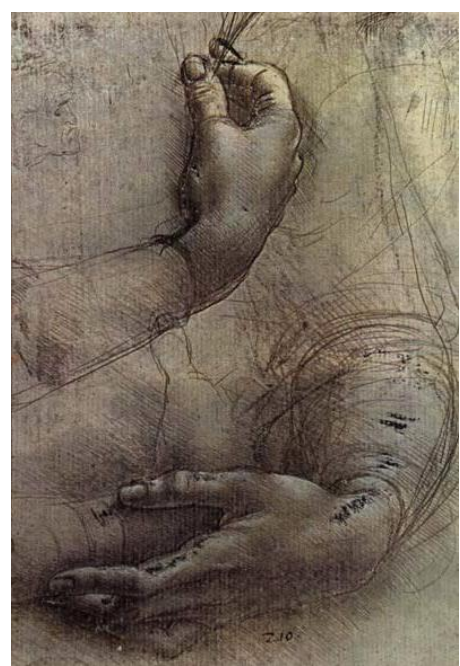

Figure 6: Leonardo da Vinci. Study of Arms and Hands. (c, 1474-75). Silverpoint and white chalk on pink prepared paper. $21.4 \mathrm{~cm} \times 15 \mathrm{~cm}$ (This sketch is considered to be a preliminary study for the painting "Lady with an Ermine". @ Royal Library, Winsor Castle, UK)

3) Discussion: Artists Methos, Highlighting Differences.

a) Jehan (Jan) Van Eyck, was born in Maaseik, Bishopric of Liege, nowadays Belgium c.1395 and died in Bruges c. 1441. He was the first Flemish painter to achieve newly 
Volume 4 Issue 15 (December 2021) PP. 100-118 DOI 10.35631/IJHAM.415009

international fame perfecting the technique known as oil painting method (Leon, 2021). He transformed gothic painting into something fresh and influential, characterized by minutely realistic depictions of surface effects and natural light; made possible by using the oil medium allowing for the building up of translucent layers or glazes of paint. Van Eyck already belonged to a family of painters in Liège. He probably got his start in miniature, given the detail of his work and his refined technique. In 1425 van Eyck became the official court painter of Philip the Good, duke of Burgundy (r.1419-1467). His naturalism was certainly a rarity in his day. This, added to the meticulousness of his painting, the precision in the textures and lighting, and the new quest to create the illusion of perspective made Van Eyck almost a scientist (Kleiner, 2010, p. 400). About 20 surviving paintings are attributed to him from the period of c. 1430 until his death in 1441, but not all are unanimously acknowledged and accepted, including the 'Ghent Altarpiece'. Some illuminated miniatures and portraits were made by members of the workshop during his life time or roughly within a decade after the master's death (Borchert, 2016, p. 73). He painted single panels, diptychs, triptych, and polyptych panels as well as both secular and religious subjects. Van Eyck was well versed in the use of silverpoint as preparatory portrait drawings for oil painting; the "old man" (Cardinal Niccolò Albergati) dating from c. 1431, is the only undisputed drawing by Van Eyck that survives. It was probably one of the 200 drawings from the KupferstichKabinett of Dresden collection sometime before 1764 (Hickley, 2020). Arguably Van Eyck drew the sitter likeness from life and subsequently produced a remarkably detailed drawing for the painted portrait. At least two different metalpoints were used for correction in the contour drawing, carefully modelling the sitter's physiognomy with subtle hatching strokes (Borchert, 2016, p. 74). Although certain silverpoint portrait drawings have been attributed to Van Eyck, however the manner in which they have been created raises doubts about the hand and skilled draughtman betraying the Master's limitation. (Figure 7: (a) and (b), below)

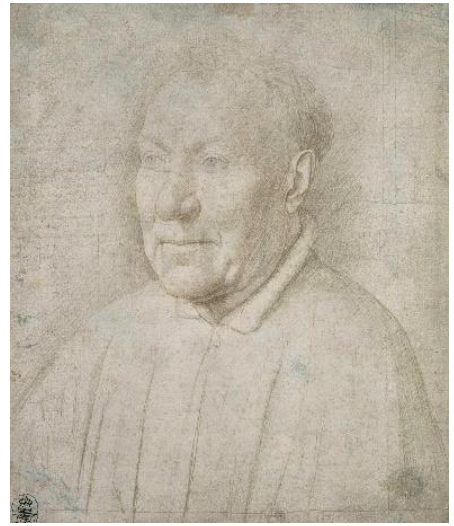

a)

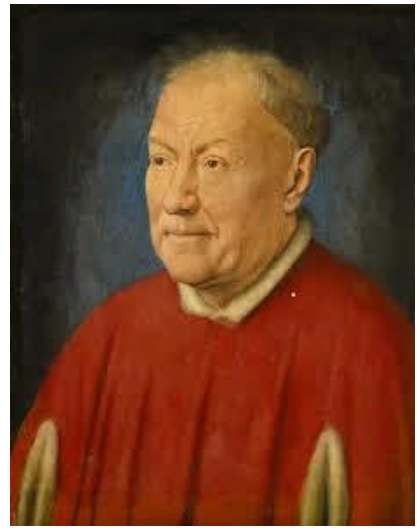

b)

Figure 7: Jan van Eyck (c, before 1390-1441): (a) Portrait of a man, Niccolò Albergati. Silverpoint drawing. (c, 1431)

(b) Portrait of Cardinal Niccolò Albergati. (c, 1431). 275 x 340 mm. Oil on board. (Kunsthistorisches Museum, Vienna, Austria) 
Volume 4 Issue 15 (December 2021) PP. 100-118 DOI 10.35631/IJHAM.415009

The paper used for this preliminary drawing is linen rag paper, that has been primed probably with calcium phosphate, which is the quality of bone white and provides a smooth surface and enough abrasiveness for the metalpoint to adhere to. Usually poultry bones were used, their hollow structure allows a faster reaction combined to a watery suspension with dilute gelatinous animal glue, which was then applied with a brush. This surface was ready to receive the tracing with a metalpoint stylus (Wallert et al., 2016, p. 28), once it was smoothed to an off-white finishing. Silverpoint lines are particularly inclined to tarnish as a consequence of the moisture of the air, the result is rapid transmission from bluish-grey to a warmer purple-grey colour. The gold-point would remain unchanged. Artists might draw with different metal points for their artworks; a painting from the studio of Dieric Bouts the Elder, 'St. Luke Drawing the Virgin and the Child', (c. 1440-1475) depict an evangelist in the act of drawing holding a stylus with two distinct metal points at each end. The styluses are examples of meticulous craftsmanship (Wallert et al., 2016, p. 31) (Figure 8: a, b, beneath).

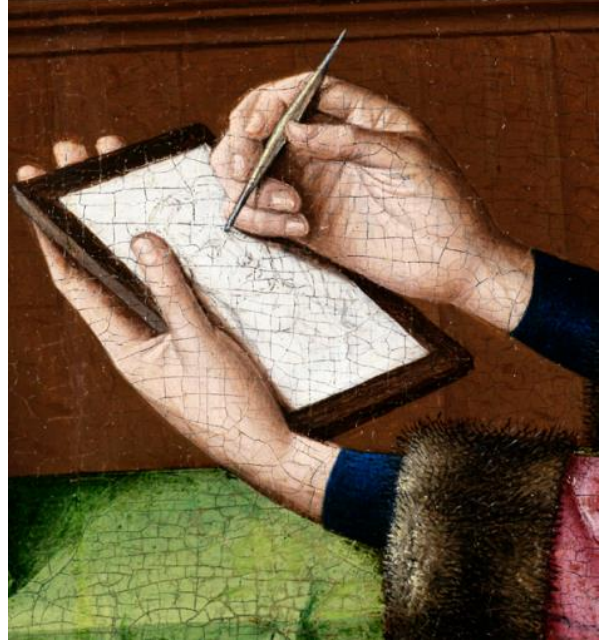

a)

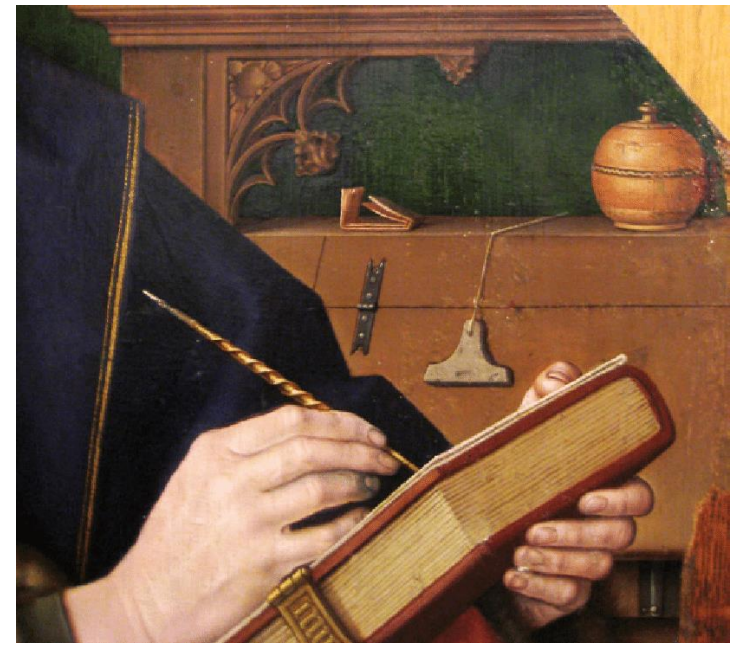

b)

Figure 8: (a) Dieric Bouts (born c, 1415-1475). St. Luke Drawing the Virgin (detail), c. 1440-1475. Oil on Panel. $109 \mathrm{~cm} \times 86.5 \mathrm{~cm}$. (National Trust Penrhyn Castle). (b) Hugo van der Goes (c, 1430/1440-1482) (attributed to). St Luke Drawing the Madonna (detail). c, 1470. Oil on panel. $104 \mathrm{~cm}$ x $62.5 \mathrm{~cm}$. (Museu Nacional de Arte, Lisbon)

Iron as a raw metal does not leave any mark on coated or un-coated paper. Its sole purpose is to make an incision in the substrate surface for subsequent sketching or painting. Lead-rod does leave marks on un-coated or coated paper. It is important to highlight that the underneath drawings in Van Eyck paintings does not present the character of sketches. They are works of art complete in themselves and their prime importance is attested by the fact that the definitive painted version superimposed upon them, corresponds as a rule, to the elements of the drawing beneath (Desneux, 1958, p. 13). (Figure 7: above)

\section{b) "A grandson of mine was born son of Ser Piero my son, on April 15 Saturday at}

three o'clock in the night. His name was Leonardo", who was born in the village of Anchiano near the town of Vinci in 1452 (Bedini, 1990, p. 12). The grandfather following the notary's costume recorded the birth of Leonardo. The 67 years that make-up Leonardo life span included one of the most tumultuous and creative eras in human history. Events during that period set 
Volume 4 Issue 15 (December 2021) PP. 100-118 DOI 10.35631/IJHAM.415009

the stage for the modern world and the great rebirth of the human spirit, the Renaissance was reaching its pinnacle when Leonardo was born (Bedini, 1990, p. 10). Italian artists were favoured, not only because they were very great as artists but they also represented the spearhead of the culture of their time. (Bedini, 1990, p. 22). Most of the artists around Leonardo's time had access to a limited range of available drawing tools, which they exploited with unparalleled inventiveness. From 1470-80, Leonardo used metalpoint for sketching life objects or looser mediums such as pen and ink, red-black chalks for anatomical studies on paper made from clothing rags of hen or linen usually white but occasionally blue. During Leonardo's lifetime, paper became an everyday commodity encouraging artists to use it more freely and experimentally. To begin, consider 'what was a drawing for Leonardo?' 'For the artist, drawing is discovery. It is the act of drawing that forces the artist to look at the object in-front of him, to dissect it in his mind's eyes and to put it together again (165)', said John Berger (1972) in his book 'Selected Essays and Articles: The Look of Things' published in 1972. Leonardo da Vinci, is the greatest draughtsman in Western art, technically he was brilliant in whichever medium he utilised. Silverpoint among other mediums and materials drove his creative and scientific imagination. In Milan, Leonardo schooled his students in silverpoint, but this approach fell out of favour after his death (Norreys, 2020). To prime the handmade paper, the ground preparation was a mixture of bone ash, red pigment, rabbit glue added to clean water pounded together into a soft and fine mixture (Trust, 2019). The bear walking and a study of its paw, an anatomical drawing of a dissected foot of a bear dated around 1482-85, were possibly made from the same animal (Popham, 1937, p. 87).

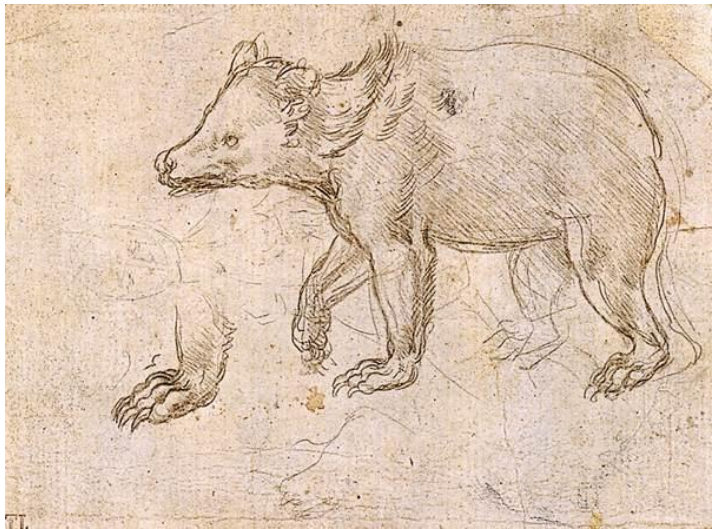

a)

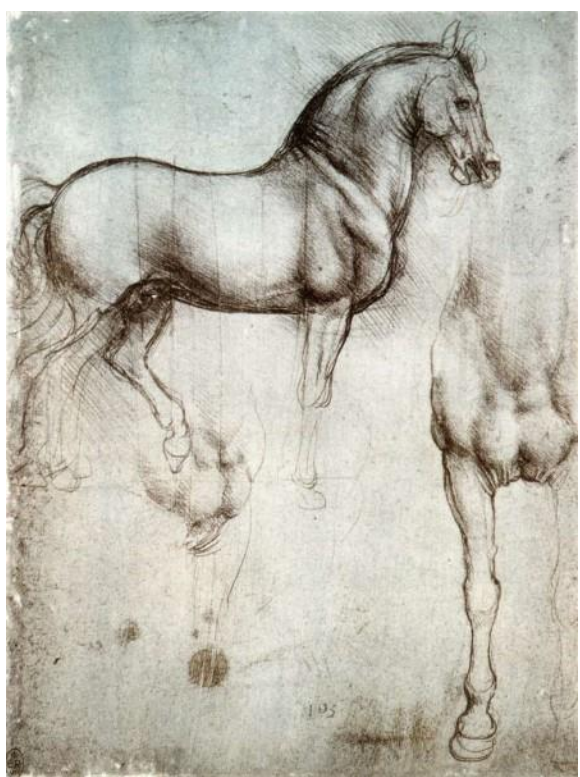

b)

Figure 9: Leonardo da Vinci (1452-1519). Silverpoint on pink-beige prepared paper (a) A Bear Walking. (c. 1482-85). $10.3 \mathrm{~cm} \times 13.3 \mathrm{~cm}$. (b) Drawing of a Horse. (c. 1490). Study of horses. $25 \mathrm{~cm} \times 18.8 \mathrm{~cm}$ (Royal Librarian, UK)

This drawing is related to a group of bear studies that Leonardo probably produced for his planed anatomical treatise, he wrote: 'I will discourse of the hands of each animal to show in what way they vary, as in the bear which has ligatures of the toes joined above the instep'. The 'Bronze horse' was supposed to be the most ambitious sculpture he worked on for a memorial 
Volume 4 Issue 15 (December 2021) PP. 100-118 DOI 10.35631/IJHAM.415009

monument to Francesco Sforza, father of Lodovico il Moro, art patron of Leonardo in Milan from 1491 (Bedini, 1990, p. 87). Unfortunately, it never came into fruition or took physical form. (Figure 9: (b) above)

c) Albercht Durer, (1471-1528) was an exemplarily draftsman in the study of nature;

his most explicit comment on the importance of observing nature appears in his "Vier Bucher Von Menschlicher Proportion 1528" (Four Books on Human Proportion, published shortly after his death by his wife and friend Willibrand Pirckheimer) which said: "But life in nature manifests the truth of these things. Therefore, observe it diligently, go by it and do not depart from nature arbitrarily, imagining to find the better by thyself, for thou wouldst be misled. For, verily, "art" [that is, knowledge] is embedded in nature; he who can extract it has it" (Panofsky, 2005, p. 279). Durer not only recommended the study of nature diligently but he applied this approach in a remarkable fashion, transforming the way artists depicted birds, flowers and seemingly insignificant tufts of grass (Wheelock Jr. 1999, p.19). He was a paramount figure of the German Renaissance, producing a significant number of paintings, drawings and prints. He served as positive conduit between Italy and Northern Europe as an art theorist and teacher shaping the modern notion of artistic creativity and originality. He was born into a family of craftsmanship, beginning his apprenticeship at an early stage. This period would have been a formative experience transforming print-making into an autonomous art form. On July $12^{\text {th }}$ of $1520-1521$, Durer started a journey to the Netherlands, accompanied by his wife and maid. The reasons for this trip are still debated; however, he travelled extensively, making excursions to Brussels, Cologne, Middel-burg, Antwerp, Aix-la-Chapelle, Ghent and Bruges. He completed a number of silverpoint drawings. (Gigg, 1985, p. 405). Although Vasari also praised Durer's craftsmanship, he insisted in the 'Lives of the most excellent Painters, Sculptors and Architects' (Le Vite 1550), that 'designo'- drawing, has a good beginning unless it comes from continual practice in copying nature. This concept of imitation permeated many fields of endeavour. Durer portrayed himself in silverpoint during his childhood, the uniqueness of the sketch strokes presented no concern to him. The text read; 'Here I portrayed myself from a mirror in the year 1484, when I was still a child' (Smith, 2011, p. 38); Durer was preoccupied with the issue of his artistic fame enduring. He was a very systematic person in recording, making little notations or remarks at all stages of the development of his artistic production, even making later notations, such as updating remarks in previous working drawings (Figure 10: beneath). 


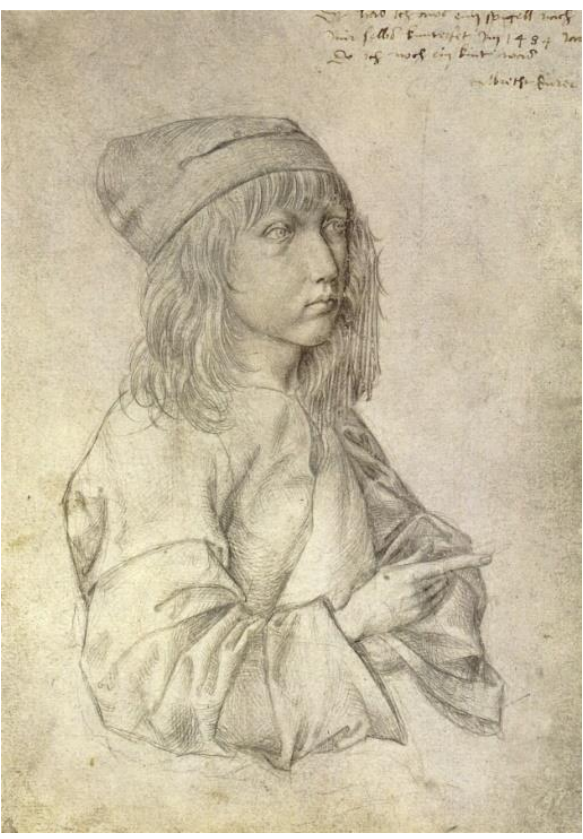

a)

Figure 10: (a) Albrecht Dürer: Self-Portrait at Thirteen, 1484. Silverpoint on prepared paper overall: $27.3 \times 19.5 \mathrm{~cm}$. (Albertina Museum, Vienna Austria) (b) Dog drawings 1520-21. Silverpoint over trace under-drawing in black on prepared paper. (This sketch forms part of a drawing executed during his trip to the Netherlands) (British Museum)

d) Susan Schwalb, an American contemporary visual abstract painter born in 1941, New York.

Dr. Weber, curator, introduces Susan Schwalb as one of the leading practitioners of metalpoint in the United States, pushing back the boundaries of the medium and substantially enriching its expressive vocabulary (Weber, 2018, p. 11). Most of the contemporary artists who draw with a metal stylus continue the tradition of the old masters by using soft and delicate lines for figurative imagery. By contrast Schwalb, while challenging the traditional way of drawing, produces works which are absolutely abstract in handling the technique. She is extremely innovative; paper is torn or burned to provide an emotionally free and dramatic contrast to the impression of the silverpoint line. The peculiarities of the diverse metal-rods used by Schwalb, such as gold, silver, aluminium, pewter, bronze, brass, and platinum, allows for soft swirls of tones and colours and causes ephemeral qualities and a shimmering luminosity. The artist prepares the substrate and explores the nuances of the different metals by carefully selecting the surface colour of pigmented gesso such as black, red, yellow, blue or green; taking advantage of the paper and other surfaces to accentuate the complex interplay of the many gradations of line and colours (figure 11: a, b, beneath). For Schwalb the medium has served as a vehicle for advancing individual artistic expression while reinvigorating the Renaissance tradition of exquisite craftsmanship (Weber, 2018, p. 11). 


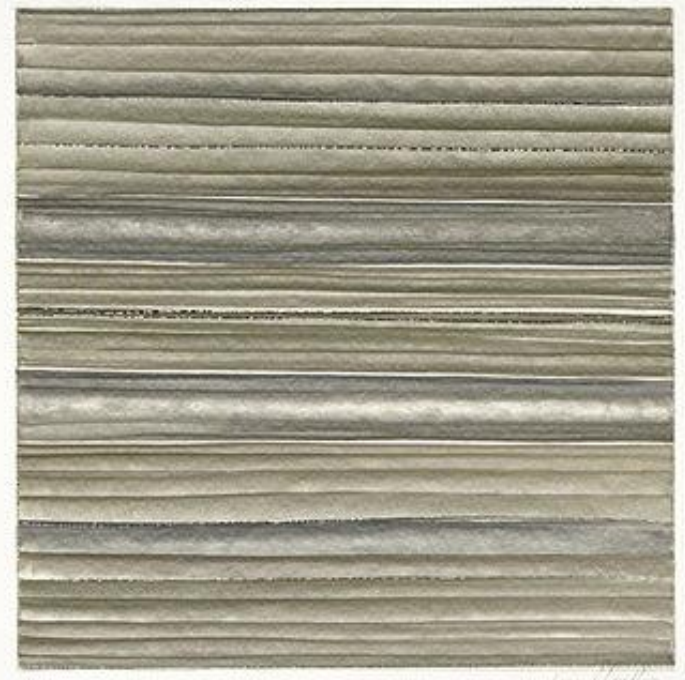

a)



b)

Figure 11: (a) Strata \# 505. 2020. Silver, aluminium, gold, copper, brass on video media paper. (b) Parchment (4V81), 1981-82. Copper-point, fire, smoke on clay coated paper.

e) Carol Prusa, is another American contemporary visual artist born in 1956 in Chicago;

She is well-known for her meticulous large-scale silverpoint, mixed medium and un-expected materials from sculpted resin and fiberglass to metalpoint, LED light with a focus on astrophysics. Prusa's, creates intriguing beautiful artifacts which appear to be from another world. Beitmen (2017) introduces Prusa's works from the exhibition catalogue: "Thin Spaces 2017", Art Center Sarasota, as 'Fractal and Tessellated surfaces revelling brilliant mathematical intelligence while pointing to realities beyond their materials trapping' (5). The Artist remembers looking out through the window at the night sky feeling and asking her-self about the 'overwhelming immensity" of space (Strickland, 2019). Prusa's works are at their best associated with the great mathematical artist M.C. Escher. In 1963 Escher declared: "If you want to express something impossible, you must keep to certain rules. The element of mystery to which you want to draw attention should be surrounded and veiled by a quite obvious, readily recognizable commonness" (Poole, 2015). Humans have had an intrinsic interest in the world that they inhabit since pre-historic times, so men are used to mapping the stars for movement and travel, recording the discovery of new lands for their socio-economic purposes, and using maps to record the new flora and fauna discovered. From the Greeks to the Romans, from the Middle Ages and throughout modern times, every human generation has mapped the globe for different reasons. Prusa's constructed fiberglass-gesso domes explore a number of models developed to explain our universe. The mathematics and the geometries offer a spiritual force that organizes structures from the microscopic to the political. The geometry in her works is simply abstract but creates a real world sustained by its own logic. She also utilizes 3D software to generate complex geometries and model emergent behaviour. Galileo, in the book 'The Assayer 1623' stated that the universe was written in the language of mathematics and it characters were triangles, circles and other geometric forms... likewise the works of Prusa are a symphony of forms and colours comprising the 3D fiberglass domes, articulated with silverpoint drawings and graphite on the convex illuminated surfaces, punctuated by patterns of light with some incorporating videos (Alexander, 2010). 




a)

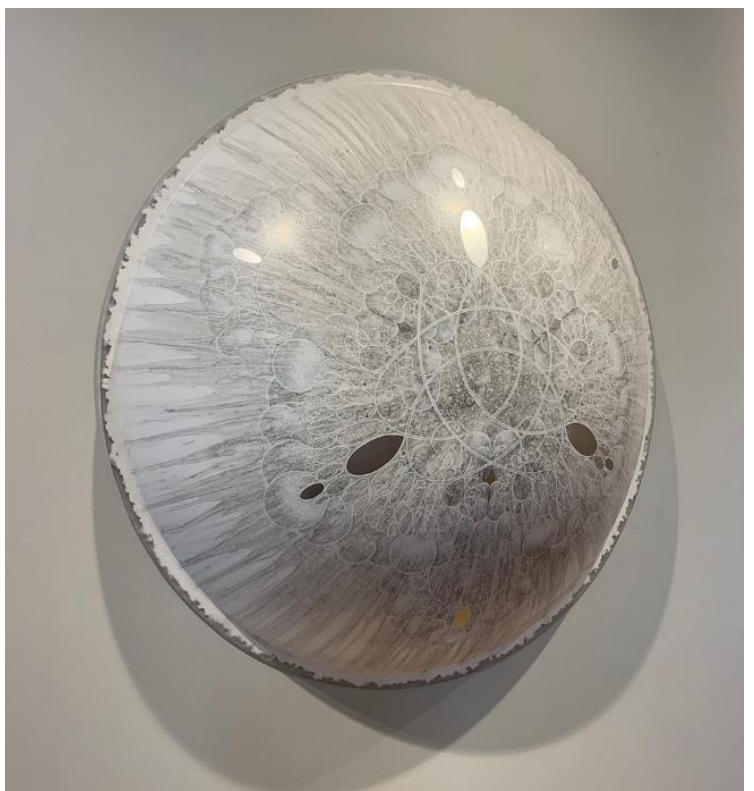

b)

Figure 12: 3D Domes, (a) work on progress, Fiberglas, gesso, silverpoint, Ink, LED lights. (b) Fiberglass, gesso, silverpoint and LED light, $2010.120 \mathrm{~cm} \times 120 \mathrm{~cm} \times 35 \mathrm{~cm}$

The 3D domes are custom made, then are covered with a layer of gesso, sanded to its ideal smoothness and then Prusa proceeds to draw over it with silverpoint. This first stage Prusa calls 'ego driven'; then a light wash of graphite colour is given to obliterate her drawn images. She then waits for new images to emerge and disclose images she had neither intended nor foreseen. Then, she proceeds to use white titanium pigment to infuse luminosity highlighting the images that she has selected from the unexpected emergence, engaging the dialectic of 'ego driven' and 'non-ego-driven. Ultimately, holes are drilled from which the lights will emanate. Over these precise lines, the artist re-draws nebulous forms that feel 'part biological and part stardust clouds', she says, "we are all tethered to the singularity of the Big Bang. We are born of stardust" (Mcintosh, 2020.)

\section{Conclusion}

In drawing a single line using a metalpoint tool is used for modelling the object form. It can either follow the object contour or be built by hatching or cross-hatching lines in the opposite direction, giving the object 'mass and volume'. The metalpoint method of drawing is a unique, demanding, and challenging medium to master, yet in the hands of skilled draughtsmen, it delivers stunning results. Contemporary artists are re-examining its potential using it to unearth unexpected and surprising creative possibilities. From the artist's perspective it is neither a difficult technique nor an easy method to employ, yet it requires time to master. Metalpoint requires intense pre-meditation for each single stroke. The artist must use a short length metal rod placed in a stylus, (similar to a mechanical pencil holding the metal rod) and trace marks on a coated surface making it difficult to be erased. Unlike charcoal, chalk or graphite the artist cannot darken the marks by varying the pressure. Strokes in general have a light tonal value. Dark areas of the drawing can be created by methodically repeating strokes like hatching or cross-hatching patiently, from velvet to steel, from muscular flesh to dewy rose petal, this has to be achieved by the exacting touch of the tip. In term of durability metalpoint is midway between drawing and etching. Given the limitations and challenges that this medium presents, Copyright $\odot$ GLOBAL ACADEMIC EXCELLENCE (M) SDN BHD - All rights reserved 
Volume 4 Issue 15 (December 2021) PP. 100-118

DOI 10.35631/IJHAM.415009

it is unsurprising that it has fallen out of favour and has been supplanted by other easier mediums such as graphite. There is a need to add to the conversation on Old Master's drawing approach with new knowledge. While technical data cannot replace connoisseurship, knowledge, experiences and expertise may provide useful information to comprehend the material choices of specific artists. It is a mystery why some artists chose metalpoint and why it appears and then disappears in some countries. Leonardo used it, but Michelangelo did not. Perhaps the results outlined in this article may serve as a springboard for future research. Artistic techniques are not difficult in and of themselves; rather, the artist needs to accumulate knowledge via experience and studies to comprehend how materials interact with one to another in order to maximize their potential throughout the creative process. There are unlimited options for artistic expression with this capability and the diversity of materials available on the market. Contemporary artists have pushed the boundaries of the materials combining and creating astonishing artworks. Finally, learning is directly tied to the experience of art, the smell, the feel and the touch provides a foundation for the artist to build upon, to become an explorer of the mediums, expanding their limitations, this could have been one of the approaches taken by the old masters in their trial-and-error quest to use metalpoint for their drawings during the early days of the Middle Ages and the Renaissance.

\section{References}

Alexander, N. (2010). Emergence by Carol Prusa. Catalogue Published by Coleman Burke Gallery. Source from, https://www.carolprusa.com

Alfeld, M., Cagno, S., Dik, J., Schaeps, J., Appel, K ., \& Jannsens, K. (2009). Investigation of a $15^{\text {th }}$ Century silverpoint via $\mu-X R F$. Source from,

https://www.researchgate.net/publication/47513066_Investigation_of_a_15th_century _silverpoint_drawing_via_-XRF

Anderson, D. M, Nash, Ray, Turner, Eric Gardner, Brown, T. Julian, Williams, Robert, PinderWilson, Ralph H. and Barbour, Ruth (2019, February 22). Calligraph drawing via uy. Encyclopedia Britannica. https://www.britannica.com/art/calligraphy

Antoine, B. (2007). Metalpoint Drawing: The History and Care of a Forgotten Art. Pp 3. Source from, http://www.bethantoine.com/research/Metalpoint_Final.pdf

Bedini, S., Brizio, A.M., Brugnoli,M.V., Chastel, A., Dibner, B., Ludwing H. Heydenreich, Marinoni, A., Reti, L., Winternitz, E., \& Zammattio, C. (1990). The Unknown Leonardo. Abradale Press. Harry N. Abrams INC. Pp 10.

Beitmen, L.R. (2017). Thin Spaces, Carol Prusa, Voids wall cluster filaments. Catalogue Art Center Sarasota Published. Source from, http://www.carolprusa.com/wpcontent/uploads/2017/09/ThinSpaces_PRUSA_Ebook.pdf

Berger, J. (1972). Selected Essays and Articles: The Look of Things. Harmondsworth and New York Penguin. Pp 165.

Borchert ,Till-Holger (2016). Some Remarks on Drawing by Jan Van Eyck, His Workshop and His Followers. STAH la pensée, Vol. 6. Source from, https://vlaamsekunstcollectie.academia.edu/TillHolgerBorchert

Britannica, T. Editors of Encyclopaedia (2003, March 11). pencil drawing summary. Encyclopedia Britannica. https://www.britannica.com/summary/pencildrawing

Britannica, T. Editors of Encyclopaedia (2016, October 18). metal point. Encyclopedia Britannica. https://www.britannica.com/art/metalpoint

Burns, T. (2011). Cennino Cennini's Il Libro dell'Arte: A Historiographical Review. Studies in Conservation, 56. (01). Pp1-13. Source from, https://www.jstor.org/stable/42751734 
Volume 4 Issue 15 (December 2021) PP. 100-118 DOI 10.35631/IJHAM.415009

Cumming, L. (2015). Drawing in Silver and Gold: From Leonardo to Jasper Johns review sensationally beautiful. The Guarding, The Observer, Art. Culture Section. Source from, https://www.theguardian.com/artanddesign/2015/aug/30/drawing-silver-goldleonardo-jasper-johns-review-biritish-museum

Dahn, K. (2004). The Stylus revealed: A Metalpoint Identification Study of Fifteenth and Sixteenth Century Italian Drawing in the Metropolitan Museum of Art. Paper Conservator. 28. Source from, https://doi.org/10.1080/03094227.2004.9638642

Desneux, J. (1958). Underdrawings and Pentimenti in the Pictures of Jan Van Eyck. The Art Bulletin. 40(01) Pp 13-21. Source from, https://www.jstor.org/stable/3047745

Dik. J, Janssens. K., \& Geer Van Der Snickt, (2008). Silverpoint under-drawing? A Note on Its Visualization with Synchrotron Radiation Based X-ray Fluorescence Analysis. Source from, https://www.researchgate.net/publication/233131508

Gigg, R. (1986). 'Studies of Durer's Diary of His Journey to the Netherlands: The Distribution of the Melencolia I'. Zeitschrift Fur Kunstgeschichte. 49(3). Pp 398-409. Source from, https://www.jstor.org/stable/G1482363

Gombrich, E.H. (1979). The Sense of Order, A study in the Psychology of Decorative Art. Phaidon. Pp. 94.

Hellmut, W. (1984). Drawing in the Early Renaissance by Ames-Lewis. The Art Bulleting Vol, 667. No. 2. Pp 335-33. Source from, https://doi.org/10.2307/3050430

Hickley, C (June, 12. 2020). 'Ultimate Masterpiece': Van Eyck drawing- rarely seen due to fragility- goes on display for the first time in a decade. The Art Newspaper. Exhibitions News. Source from, https://www.theartnewspaper.com/2020/06/12/ultimatemasterpiece-van-eyck-drawing-rarely-seen-due-to-fragilitygoes-on-display-for-firsttime-in-a-decade

Kleiner, F. (2010). Gardner's Art Through the Ages, The Western Perspective. Wadsworth Cengage Learning. Pp 400.

Krug, M. (2007). An Artist's Handbook, Materials and Techniques. Laurence King Publishing Ltd. Pp 42.

Leon, K. H. (2021, January 4). Jan van Eyck. Encyclopedia Britannica. https://www.britannica.com/biography/Jan-van-Eyck

Mcintosh, M. (2020). Cosmic Light, Adapting Classic Renaissance Silverpoint, an artist probes the Mysteries of the Universe. Luxe, Interiors + Design Magazine. A. Sandow Publication. Luxe Source. Pp 239. Source from, https://www.carolprusa.com

Morley, B. (1979). The Plant Illustration of Leonardo da Vinci. The Burlington Magazine. 121(918). Pp 553-560. Source from, https://www.jstor.org/stable/879737

Norreys, Emelina Le. (2020). Drawing After Da Vinci: Studies in Silverpoint. [Video file]. YouTube. https://www.youtube.com/watch?v=3pkludU_oP0

Panofsky, E. (2005) (Revised Edition). The Life and Art of Albrecht Durer. Publish by Princeton University Press. Pp 279.

Poole, Steven. (2015). The Impossible World of MC Escher. Art \& Design. The Guardian. Source from, https://www.theguardian.com/artanddesign/2015/jun/20/the-impossibleworld-of-mc-escher

Popham, A.E. (1937). The Drawings at the Burlington Fine Arts Club. The Burlington Magazine for Connoisseurs, (70)407. Pp 86-88. Source from, https://www.jstor.org/stable/866824

Royal Collection Trust. (2019). Leonardo da Vinci's Drawing Materials [Video file]. YouTube. $\mathrm{https}: / / \mathrm{www}$. youtube.com/watch?v=-f0ym3CtleQ\&t=199s 
Volume 4 Issue 15 (December 2021) PP. 100-118 DOI 10.35631/IJHAM.415009

Smith, J.C. (2011). Albrecht Durer as Collector. Renaissance Quarterly. 64(1). Pp 1-49. Source from, https://www.jstor.org/stable/10.1086/660367

Speed, H. (1972). The Practices and Science of Drawing. Dover Publication INC. New York. $\operatorname{Pp} 31$.

Strickland, A. (2019). Mesmerizing cosmic artworks honor history's unsung female astronomers by Carol Prusa. CNN Style. Arts. Source from, https://edition.cnn.com/style/article/carol-prusa-dark-light-exhibition-scn/index.html

Wallert. A, Reissland. B, \& Menges, L. (2016). A Metalpoint drawing by Jan Van Eyck? Notes on the Materials Aspects. Source from, https://www.researchgate.net/publication/290965164_A_metalpoint_drawing_by_Jan _van_Eyck_Notes_on_the_Material_Aspects

Weber, B. (2018). A Luminous Line, forty years of Metalpoint Drawings by Susan Schwalb. Catalogue Publish by Arkansas Arts Center. Pp 7. Source from, https://www.garveysimon.com

Wheelock Jr, A.K. (1999). Catalogue: From Botany to Bouquests, Flowers in Northern Art. Edited by National Gallery of Art, Washington. Pp 19. 